\title{
В.В. Иванов
}

\section{ИНСТРУМЕНТЫ НАЛОГОВОГО СТИМУЛИРОВАНИЯ РЕСУРСОСБЕРЕГАЮЩЕЙ МОДЕЛИ РАЗВИТИЯ НАЦИОНАЛЬНОЙ ЭКОНОМИКИ ${ }^{1}$}

\begin{abstract}
Рассматриваются проблемные аспекты стимулирования инвестиционной активности российских компаний. Показано, что в условиях стагнации национальной экономики применяемые инструменты налогового стимулирования не обеспечивают желаемого роста инвестиций в основные средства предприятий во многих сферах экономической деятельности. При этом наблюдается значительный рост финансовых вложений предприятиями реального сектора экономики на финансовом рынке России. Обосновывается иелесообразность смещеения акцентов с налогообложения доходов юридических лии на налогообложение используемых ими ресурсов, а также необходимость создания сбалансированной системы налогообложения предприятий, организаций реального $и$ финансового секторов начиональной экономики.

Ключевые слова: налоговое стимулирование, инвестиционная активность, экономический рост, налоговые преференции, финансовая помощь.
\end{abstract}

\section{Введение}

Налоговое стимулирование включает в себя комплекс побуждающих налогоплательщиков к «определенной модели поведения, отвечающей интересам государства» [1, с. 25]. Представляется, что такой моделью для России должна стать инновационная, ресурсосберегающая модель, способная обеспечивать высокие темпы роста производительности труда, и способствовать опережающему развитию отдельных отраслей национальной экономики. Для ее реализации требуется значительный рост инвестиций в реальном секторе экономики.

В существующей модели стимулирования инвестиционной активности предприятий в РФ широко используются налоговые льготы, устанавливаемые как на федеральном, так и на региональном уровне. Мировой опыт свидетельствует о том, что налоговые льготы являются весьма противоречивым инструментом налогового регулирования инвестиционной деятельности. Практика их применения характеризуется высокой степенью неопределенности. Среди негативных последствий, в частности, выделяют:

- снижение нейтральности налоговой системы [2];

- размывание налоговой базы, что ограничивает возможности уменьшения налоговых ставок [3];

\footnotetext{
${ }^{1}$ Исследование выполнено при финансовой поддержке РФФИ в рамках научного проекта № 19-010-00198.
} 
- сложности мониторинга за целевым использованием налоговых льгот [4];

- отход от принятия рыночных решений в сфере инвестиционной деятельности [5];

- порождение разнообразных схем ухода от уплаты налогов [6];

- переложение налогового бремени с одних категорий налогоплательщиков на другие категории [7].

Оценку результативности налогового стимулирования инвестиционной активности организаций предпринимали уже во второй половине XX в. Одними из первых авторов, посвятивших исследование данной проблеме, были Р. Холл и Д. Йоргенсон [8].

Они показали позитивное влияние налоговой политики использования налоговых льгот в 1954-1962 гг. для ускоренного наращивания объемов инвестиций в США. Теоретические исследования в этой области активно развивали и другие авторы ([9-11] и др.).

Анализ фактических результатов использования налоговых льгот привел к неоднозначным выводам. Макроэкономические оценки изменения инвестиционной активности свидетельствовали как о наличии связи с налоговыми изменениями, так и об их отсутствии (см., например $[12,13])$.

В последующие десятилетия микроэкономические исследования налогового стимулирования инвестиционной активности организаций активно продолжались (см. в обзоре: [14]).

Анализу последствий использования различных способов налогового стимулирования вложений в основные фонды было посвящено исследование Е. Орна [15]. Он соотносил льготы, связанные с ускоренной амортизацией основных средств, и снижением ставки налога на прибыль для корпораций в США по отдельным направлениям их деятельности. Им был сделан вывод о том, что оба инструмента стимулирования инвестиционной активности обеспечивают сопоставимую результативность.

В XXI в. анализ инструментов налогового стимулирования дополняется и оценкой их восприятия бизнес-сообществом [16], в том числе с учетом национальных специфик [17] и конкретных экономических условий [18]. В частности, Дж. Джоли [19] с соавт. провели опрос топменеджеров компаний в США, имеющих и не имеющих права на использование налоговых льгот, на предмет предпочтительности инструментов стимулирования инвестиционной активности и создания рабочих мест. Большинство руководителей в обеих группах высказали предпочтение снижению ставки налога на прибыль, а не предоставлению налоговых льгот. При этом следует отметить, что лишь треть руководителей компаний, имевших право на инвестиционную налоговую льготу, были о ней осведомлены.

Исследования инвестиционного поведения представителей малого и крупного бизнеса $[20,21]$ показали различие взглядов на налоговые стимулы повышения инвестиционной активности. Исследовались и отраслевые особенности влияния налоговых льгот на инвестиционную активность компаний [22]. 


\section{Факторы, влияющие на инвестиционную деятельность компаний}

Проведенные нами исследования влияния налоговых льгот на инвестиционную активность предприятия показали различную направленность использования высвобождающихся средств от предоставления налоговых льгот в зависимости от стадии жизненного цикла организации [23]. Предприятия заинтересованы наращивать инвестиционную активность до тех пор, пока растет фондоотдача. В дальнейшем их интерес состоит в поддержании приемлемого уровня капиталоемкости. Потребности же в соответствующих источниках финансирования инвестиционной активности как для выхода на желаемый уровень капиталоемкости, так и для его поддержания существенно различаются в зависимости не только от общего состояния экономики, так и от стадии жизненного цикла организации.

\section{Таблица 1. Распределение налоговых расходов ${ }^{1}$ в разрезе функциональной классификации расходов в 2015-2021 гг., млрд руб.}

\begin{tabular}{l|c|c|c|c|c|c|c|}
\hline & 2015 г. & 2016 г. & 2017 г. & 2018 г. & 2019 г. & 2020 г. & 2021 г. \\
\hline $\begin{array}{l}\text { Налоговые расходы } \\
\text { федерального бюджета }\end{array}$ & 1903,9 & 2017,4 & 2367,0 & 3094,7 & 3193,6 & 3286,4 & 3361,4 \\
\hline Из них: & & & & & & & \\
\hline $\begin{array}{l}\text { общегосударствен- } \\
\text { ные вопросы }\end{array}$ & 11,3 & 12,1 & 14,6 & 15,0 & 15,4 & 16,1 & 17,2 \\
\hline $\begin{array}{l}\text { национальная } \\
\text { безопасность } \\
\begin{array}{l}\text { и правоохранитель- } \\
\text { ная деятельность }\end{array}\end{array}$ & 0,7 & 1,0 & 1,0 & 1,1 & 1,2 & 1,3 & 1,4 \\
\hline $\begin{array}{l}\text { национальная } \\
\text { экономика }\end{array}$ & 1581,6 & 1666,2 & 1969,6 & 2663,3 & 2725,1 & 2783,2 & 2820,6 \\
\hline образование & 54,5 & 51,6 & 54,2 & 50,1 & 62,5 & 66,7 & 72,2 \\
\hline здравоохранение & 207,3 & 231,7 & 262,5 & 295,5 & 311,3 & 333,1 & 359,0 \\
\hline социальная политика & 37,9 & 45,8 & 57,9 & 62,2 & 69,0 & 76,2 & 80,5 \\
\hline $\begin{array}{l}\text { средства массовой } \\
\text { информации }\end{array}$ & 7,4 & 7,8 & 9,0 & 10,4 & 11,2 & 12,0 & 12,9 \\
\hline
\end{tabular}

\section{Источник: [24].}

Как следует из данных, приведенных в табл. 1, в течение 2019-2021 гг. планируется ежегодный рост налоговых расходов федерального бюджета в объеме порядка 100 млрд руб., подавляющую часть которых составляют налоговые льготы. Основные объемы налоговых льгот предоставляются

${ }^{1}$ Под налоговыми расходами в Основных направлениях бюджетной, налоговой и таможенно-тарифной политики на 2019 г. и плановый период 2020 и 2021 гг. понимаются выпадающие доходы бюджета, обусловленные налоговыми льготами, освобождениями и иными преференциями по налогам, сборам и таможенным платежам, предусмотренными в качестве мер государственной поддержки в соответствии с целями государственных программ и (или) целями социально-экономической политики, не входящими в государственные программы. 
предприятиям реального сектора национальной экономики. Ее доля в общем объеме налоговых расходов федерального бюджета в 2015-2018 гг. составляла около $83 \%$.

Рост налоговых льгот и, соответственно, увеличение собственных средств предприятий слабо отражаются на их инвестиционной активности. В 2014-2017 гг. рост инвестиций в основном наблюдался в сфере добычи полезных ископаемых, в сельском хозяйстве (в текущих ценах рост составил соответственно 45,8 и 31,4\%). Рост же инвестиций в целом по обрабатывающим производствам, в организациях социальной сферы в указанный выше период не превышал уровня инфляции либо сокращался. Объемы инвестиций в сфере «обрабатывающие производства» за указанный период выросли в текущих ценах на $15,1 \%$, а в производстве машин и оборудования инвестиции сократились с 61,7 до 47,6 млрд руб. Рост инвестиций наблюдался преимущественно в отраслях с высоким уровнем рентабельности (табл. 2).

Приведенная статистика вызывает сомнения в эффективности налоговой льготы как инструмента стимулирования инвестиционной активности предприятий.

\section{Таблица 2. Состав и структура инвестиций в основной капитал организаций и финансовые вложения, не относящиеся к субъектам малого предпринимательства}

\begin{tabular}{|c|c|c|c|c|c|c|}
\hline & \multicolumn{2}{|c|}{$\begin{array}{l}\text { Инвестиции в ос- } \\
\text { новные средства, } \\
\text { млрд руб. }\end{array}$} & \multicolumn{2}{|c|}{$\begin{array}{c}\text { Финансовые вложения, } \\
\text { млрд руб. }\end{array}$} & \multicolumn{2}{|c|}{$\begin{array}{c}\text { Рентабельность про- } \\
\text { данных товаров / рен- } \\
\text { табельность активов, } \\
\%\end{array}$} \\
\hline & 2014 г. & 2017 г. & 2014 г. & 2017 г. & 2014 г. & 2018 г. \\
\hline Всего & 9852,9 & 12256,3 & 78604,4 & 165669,2 & $8,6 / 3,9$ & $8,1 / 6,4$ \\
\hline $\begin{array}{l}\text { Сельское хозяй- } \\
\text { ство }\end{array}$ & 304,3 & 400,0 & 374,1 & 815,3 & $18,4 / 5,7$ & $16,8 / 6,8$ \\
\hline B\% китогу & 3,1 & 3,3 & 0,5 & 0,5 & & \\
\hline $\begin{array}{l}\text { Добыча полезных } \\
\text { ископаемых }\end{array}$ & 2013,9 & 2936,7 & 5965,8 & 13094,9 & $22,2 / 14,6$ & $27,2 / 10,0$ \\
\hline B\% итогу & 20,4 & 24,0 & 7,6 & 7,9 & & \\
\hline \multicolumn{7}{|l|}{ Из них: } \\
\hline $\begin{array}{l}\text { добыча топлив- } \\
\text { но-энергетичес- } \\
\text { ких полезных } \\
\text { ископаемых }\end{array}$ & 1841,2 & 1986,9 & 4826,1 & 6726,4 & $20,7 / 15,6$ & $23,8 / 8,1$ \\
\hline в\% и итогу & 18,7 & 16,2 & 6,1 & 4,0 & & \\
\hline $\begin{array}{l}\text { Обрабатывающие } \\
\text { производства }\end{array}$ & 1748,8 & 2014,7 & 14466,4 & 22632,0 & $10,7 / 2,3$ & $10,5 / 6,6$ \\
\hline в\% к итогу & 17,7 & 16,4 & 18,4 & 13,7 & & \\
\hline \multicolumn{7}{|l|}{ Из них: } \\
\hline $\begin{array}{l}\text { - производство } \\
\text { машин и оборудо- } \\
\text { вания }\end{array}$ & 61,7 & 44,5 & 330,1 & 485,0 & $6,8 / 1,3$ & $7,4 / 5,2$ \\
\hline в\% \% итогу & 0,6 & 0,4 & 0,4 & 0,3 & & \\
\hline
\end{tabular}




\begin{tabular}{l|c|c|c|c|c|c|}
\hline & \multicolumn{2}{|c|}{$\begin{array}{l}\text { Инвестиции в ос- } \\
\text { новные средства, } \\
\text { млрд руб. }\end{array}$} & \multicolumn{2}{|c|}{$\begin{array}{c}\text { Финансовые вложения, } \\
\text { млрд руб. }\end{array}$} & $\begin{array}{c}\text { Рентабельность про- } \\
\text { данных товаров / рен- } \\
\text { табельность активов, } \\
\%\end{array}$ \\
\hline $\begin{array}{l}\text { химическое } \\
\text { производство }\end{array}$ & 228,3 & 396,1 & 1177,5 & 1235,3 & $22,4 / 0,6$ & $24,5 / 13,8$ \\
\hline в\% кттогу & 2,3 & 3,2 & 1,5 & 0,75 & & \\
\hline $\begin{array}{l}\text { - металлургиче- } \\
\text { ское производство }\end{array}$ & 201,2 & 329,1 & 1970,0 & 4244,3 & $18,7 / 4,8$ & $22,1 / 14,9$ \\
\hline в\% к итогу & 2,0 & 2,7 & 2,5 & 2,6 & & \\
\hline
\end{tabular}

Источник: рассчитано автором по: [25; 26, с. 91-93, 97, 99; 27, с. 34-37, 40].

Как явствует из данных, приведенных в табл. 3, объемы инвестиций в корпоративном секторе экономики России на протяжении 2014-2017 гг. не превышали сумм начисленной амортизации. Наибольшие объемы финансовых вложений предприятиями корпоративного сектора осуществлялись на финансовом рынке. Если инвестиции в основные средства в корпоративном секторе в 2017 г. составили 12026 млрд руб., в том числе за счет собственных средств - 6268 млрд руб., то финансовые вложения на финансовом рынке составили 165,7 трлн руб., из них 18,6 трлн руб. - долгосрочные вложения. Это означает, что значительная часть прибыли компаний корпоративного сектора национальной экономики использовалась не на инвестиции в свои основные фонды, а была направлена на финансовый рынок. Причем свободный остаток чистой прибыли после выплаты дивидендов составил в 2017 г. 6,4 трлн руб., что превышает объемы инвестиций в корпоративном секторе, осуществленные за счет собственных средств, которые составили 6268 млрд руб. (указанные данные приведены в табл. 3).

Таблица 3. Основные показатели финансовой, инвестиционной деятельности в России в 2005-2017 гг.

\begin{tabular}{l|c|c|c|c|c|c|}
\hline \multicolumn{1}{|c|}{ Показатели } & 2005 г. & 2010 г. & 2014 г. & 2015 г. & 2016 г. & 2017 г. \\
\hline $\begin{array}{l}\text { ВВП в текущих ценах, } \\
\text { трлн. руб. }\end{array}$ & 24,6 & 46,3 & 71,4 & 83,2 & 86,0 & 92,1 \\
\hline $\begin{array}{l}\text { Прирост ВВП в постоян- } \\
\text { ных ценах к предыдуще- } \\
\text { му году, \% }\end{array}$ & 6,4 & 4,5 & 1,7 & $-2,8$ & -0.2 & 1,5 \\
\hline $\begin{array}{l}\text { Доля всех инвестиций в } \\
\text { ВВП, \% }\end{array}$ & 16,7 & 19,7 & 18,9 & 16,7 & 17,0 & 17,3 \\
$\begin{array}{l}\text { Доля инвестиций корпо- } \\
\text { ративного сектора в } \\
\text { ВВП, \% }\end{array}$ & 13,4 & 14,3 & 14,4 & 12,6 & 13,1 & 13,1 \\
\hline $\begin{array}{l}\text { Инвестиции, все, } \\
\text { млрд руб. }\end{array}$ & 3611 & 9152 & 13903 & 13897 & 14640 & 15967 \\
\hline $\begin{array}{l}\text { Рост инвестиций в по- } \\
\text { стоянных ценах, \% }\end{array}$ & 3,7 & 6,3 & $-1,5$ & $-10,1$ & $-0,6$ & $-4,0$ \\
\hline $\begin{array}{l}\text { Инвестиции в корпора- } \\
\text { тивном секторе, } \\
\text { млрд руб. }\end{array}$ & 2893 & 6625 & 10377 & 10496 & 11267 & 12026 \\
\hline
\end{tabular}




\begin{tabular}{|c|c|c|c|c|c|c|}
\hline Показатели & 2005 г. & 2010 г. & 2014 г. & 2015 г. & 2016 г. & 2017 г. \\
\hline $\begin{array}{l}\text { Инвестиции в корпора- } \\
\text { тивном секторе за счет } \\
\text { собственных средств, } \\
\text { млрд руб. }\end{array}$ & 1287 & 2715 & 4742 & 5271 & 5738 & 6268 \\
\hline $\begin{array}{l}\text { Инвестиции в малых } \\
\text { предприятиях, млрд руб. }\end{array}$ & 718 & 2527 & 3181 & 3401 & 3373 & 3941 \\
\hline $\begin{array}{l}\text { Доля собственных } \\
\text { средств в инвестициях } \\
\text { корпоративного сектора, } \\
\%\end{array}$ & 44.5 & 41,0 & 45,7 & 50,2 & 50,9 & 52,1 \\
\hline $\begin{array}{l}\text { Сумма начисленной } \\
\text { амортизации в корпора- } \\
\text { тивном секторе, } \\
\text { млрд руб. }\end{array}$ & 1043 & 2669 & 4752 & 5298 & 5824 & 6350 \\
\hline $\begin{array}{l}\text { Доля амортизации в объ- } \\
\text { еме собственных инве- } \\
\text { стиций, \% }\end{array}$ & 81,0 & 98,2 & 100,2 & 100,5 & 101,5 & 101,3 \\
\hline $\begin{array}{l}\text { Прибыль до налогооб- } \\
\text { ложения, млрд руб. }\end{array}$ & 3226 & 6331 & 4347 & 7503 & 12801 & 10321 \\
\hline $\begin{array}{l}\text { Чистая прибыль после } \\
\text { налога по ставке } 20 \%, \\
\text { млрд руб. }\end{array}$ & 2580 & 5064 & 3478 & 6002 & 10241 & 8256 \\
\hline $\begin{array}{l}\text { Сумма выплаченных } \\
\text { дивидендов, млрд руб. }\end{array}$ & 223 & 1046 & 2602 & 3262 & 3841 & - \\
\hline $\begin{array}{l}\text { Свободный остаток чи- } \\
\text { стой прибыли, млрд руб. }\end{array}$ & 2357 & 4018 & 876 & 2740 & 6400 & - \\
\hline $\begin{array}{l}\text { Финансовые вложения } \\
\text { корпоративного сектора } \\
\text { на финансовом рынке, } \\
\text { трлн руб. }\end{array}$ & 9,2 & 41,3 & 78,6 & 127,1 & 136,7 & 165,7 \\
\hline $\begin{array}{l}\text { В т. ч. долгосрочные } \\
\text { вложения, трлн руб. }\end{array}$ & 1,8 & 5,0 & 9,8 & 13,8 & 15,5 & 18,6 \\
\hline $\begin{array}{l}\text { Краткосрочные финан- } \\
\text { совые вложения корпо- } \\
\text { ративного сектора, } \\
\text { трлн руб. }\end{array}$ & 7,4 & 36,4 & 68,8 & 113,3 & 121,2 & 147,1 \\
\hline
\end{tabular}

Источник: составлено автором по [28].

Представленные сведения свидетельствуют о наличии значительных резервов увеличения инвестиций в основные фонды корпоративного сектора национальной экономики, учитывая существенные объемы свободных средств, которыми располагает корпоративный сектор, в том числе и на предприятиях обрабатывающих производств. С 2014 по 2017 г. объемы финансовых вложений предприятий этой сферы на фондовом рынке увеличились с 14 466,4 до 22 632,0 млрд руб., т.е. выросли на 56,4\% (см. табл. 2).

Сложившаяся ситуация с использованием свободных финансовых ресурсов в корпоративном секторе национальной экономики обусловлена многими факторами, среди которых приоритетное место, на наш взгляд, 
занимает доходность вложений. Рентабельность проданных товаров (работ, услуг) с 2014 по 2018 г. весьма дифференцирована по отдельным видам экономической деятельности. Если в топливно-энергетическом комплексе в 2018 г. она составляла 23,8\%, то в сфере производства машин и оборудования $-7,4 \%$ (см. табл. 2 ).

Рентабельность же проданных товаров в целом по предприятиям обрабатывающих производств существенно ниже доходности вложений на Московской межбанковской валютной бирже (ММВБ), которая в среднем за 2003-2016 гг. составила 17,4\% [29].

Высокие темпы роста инвестиций в сфере добычи полезных ископаемых сопровождаются и ростом рентабельности проданных товаров (с $22,2 \%$ в 2014 г. они выросли до 27,2\% в 2018 г.). Однако следует отметить и другую особенность роста инвестиций в этой сфере. Она связана с тем, что рентабельность активов снизилась с 14,6\% в 2014 г. до 10,0\% в 2018 г. Это может являться свидетельством необходимости изменения состава и структуры основных средств в этой сфере. В противном случае темпы роста инвестиций будут уменьшаться ввиду падения фондоотдачи. О наличии такой тенденции косвенно свидетельствует и значительный рост финансовых вложений, который за указанный выше период составил 19\% и привел к росту доли финансовых вложений данного сектора национальной экономики в их общем объеме с 7,6 до 7,9\% (табл. 2).

Если рассматривать рентабельность проданных товаров в целом по российской экономике, то за период с 2014 по 2018 г. она сократилась с 8,6 до $8,1 \%$ соответственно. Это означает, что финансовая привлекательность вложений в значительную часть предприятий реального сектора экономики крайне низка (она мало отличается от размера ключевой ставки, установленной ЦБ РФ в 2018 г.). В сложившейся ситуации увеличение финансовых вложений предприятиями корпоративного сектора на фондовом рынке РФ вполне закономерно, так как финансовые ресурсы бизнеса перемещаются в те сферы, в которых они могут принести большую доходность.

Одним из приоритетных направлений повышения инвестиционноинновационной активности предприятий в литературе часто рассматривается снижение налоговой нагрузки на бизнес (см., например, [30]). Следует отметить, что налоговая нагрузка на бизнес в РФ сопоставима с налоговой нагрузкой многих развитых стран. Так, например, по расчетам Всемирного Банка в 2014 г. уровень налоговой нагрузки на бизнес в РФ составлял $47,5 \%$ от ВВП, в ФРГ - 48,9\%, во Франции - 62,6\%, в США - 43,8\% [31].

По информации министра финансов РФ А. Силуанова, представленной на Гайдаровском форуме в 2018 г., налоговая нагрузка в течение 20072017 гг. существенно варьировалась. Если в 2007 г. она составляла 36,5\% ВВП, в 2009 г. - 30,9\%, в 2014 г. - 34,7\%, то в 2017 г. она снизилась до $30,8 \%$ ВВП [32].

Столь существенные расхождения в оценках налоговой нагрузки на бизнес связаны с различием подходов к ее расчету, в частности, налоговая нагрузка Минфина РФ определяется как отношение общих налоговых дохо- 
дов госбюджета в процентах к ВВП. При этом неналоговые платежи (обязательства), например, таможенная пошлина, в расчетах не учитываются.

При анализе влияния налоговой нагрузки на бизнес важно учитывать ее дифференциацию по видам экономической деятельности. В табл. 4 приведены сведения о среднеотраслевой налоговой нагрузке и нагрузке по страховым взносам по отдельным видам деятельности.

Таблица 4. Среднеотраслевая налоговая нагрузка ${ }^{1}$ по видам деятельности в 2018 г.

\begin{tabular}{l|c|c|c|}
\hline \multicolumn{1}{|c|}{ Виды деятельности по ОКВЭД2 } & $\begin{array}{c}\text { Налоговая } \\
\text { нагрузка, \% }\end{array}$ & $\begin{array}{c}\text { Нагрузка по } \\
\text { страховым взно- } \\
\text { сам, \% }\end{array}$ & $\begin{array}{c}\text { Суммарное } \\
\text { налоговое } \\
\text { бремя, \% }\end{array}$ \\
\hline Всего & 10,8 & 3,6 & 14,4 \\
\hline Сельское хозяйство & 3,5 & 5,4 & 8,9 \\
\hline Добыча полезных ископаемых & 36,7 & 1,8 & 38,5 \\
\hline Из них: & 45,4 & 1,0 & 46,4 \\
\hline $\begin{array}{l}\text { добыча топливно-энергетичес- } \\
\text { ких полезных ископаемых }\end{array}$ & 8,2 & 2,2 & 10,4 \\
\hline Обрабатывающие производства & 4,4 & 2,4 & 6,8 \\
\hline $\begin{array}{l}\text { Из них: } \\
\begin{array}{l}\text { металлургическое производство } \\
\text { лических изделий (кроме машин } \\
\text { и оборудования) }\end{array}\end{array}$ & 8,8 & 3,9 & 12,7 \\
\hline $\begin{array}{l}\text { Производство машин и оборудо- } \\
\text { вания }\end{array}$ & 1,9 & 2,4 & 4,3 \\
\hline $\begin{array}{l}\text { Производство химических веществ } \\
\text { и химических продуктов }\end{array}$ & & & \\
\hline
\end{tabular}

Источник: рассчитано по [33].

Наибольшая среднеотраслевая налоговая нагрузка с учетом нагрузки по страховым взносам в 2018 г. наблюдалась в сфере добычи полезных ископаемых - 38,5\%. При этом налоговое бремя в сфере добычи топливноэнергетических полезных ископаемых составило 46,4\%, а рентабельность проданных товаров в 2018 г. была 23,8\% (табл. 2). Налоговое же бремя в сфере производства машин и оборудования равнялось $12,7 \%$, а в целом в сфере обрабатывающих производств - 10,4\% (см. табл. 4), т.е. в 3 раза меньше, чем в сфере добычи полезных ископаемых. При этом и рентабельность в этой сфере была также ниже, чем в сфере добычи полезных ископаемых.

Приведенные данные свидетельствуют о том, что среди факторов, влияющих на показатели рентабельности, налоговое бремя не является определяющим. Даже при весьма низком уровне налогового бремени в сфере

${ }^{1}$ По Методике Федеральной налоговой службы (Письмо ФНС от 29.06.2018 № БА4-1/12589) среднеотраслевая налоговая нагрузка рассчитывается как отношение суммы уплаченных налогов в бюджеты разных уровней, включая НДФЛ, к суммарной выручке по данным бухгалтерского учета организаций, отнесенных к конкретному виду деятельности, за конкретный год в процентах. 
обрабатывающих производств имеет место низкая рентабельность проданных товаров (работ, услуг) и практически отсутствует рост инвестиций в основные фонды при значительных объемах финансовых вложений в инструменты финансового рынка страны. Отдельного рассмотрения требует нагрузка по страховым взносам, которые работодатели перечисляют во внебюджетные фонды. Для многих видов деятельности эта нагрузка является весьма существенной. В частности, в сфере производства машин и оборудования она составляла в 2018 г. 44,3\% от собственной налоговой нагрузки. Высокие ставки страховых взносов во внебюджетные фонды в размере $30 \%$ от фонда оплаты труда, по мнению министра финансов РФ А. Силуанова, являются одной из основных причин наличия масштабного «теневого» сектора в российской экономике [34].

По оценке Центра социально-политического мониторинга РАНХиГС, в «теневом» рынке труда в 2017 г. находилось около 33 млн чел., что составило 44,8\% всех занятых. К этой категории отнесены лица, которые получали заработную плату в «конвертах», а также лица, которые имели «неоформленные» работы [34].

На наш взгляд, снижение ставок страховых взносов во внебюджетные фонды необходимо осуществить как можно быстрее, ориентируясь при этом на средние ставки по странам, входящим в ОЭСР. Однако это вряд ли позволит кардинально решить в Российской Федерации проблему снижения уровня теневой экономики до средних показателей теневой экономики в странах ОЭСР. Наряду со снижением ставок страховых взносов важно создать условия, при которых «обналичка» финансовых ресурсов предприятий будет им экономически невыгодной.

По нашему мнению, было бы целесообразным заменить налог на прибыль налогом на расходы по обычным видам деятельности (расходы, включаемые в себестоимость произведенной продукции, работ, услуг, коммерческие, управленческие расходы) и прочие расходы, учитываемые при исчислении прибыли, за исключением расходов на оплату труда, налогов, страховых взносов и иных платежей в бюджеты, начисленной амортизации, включаемых в себестоимость продукции. Ставки предлагаемого налога должны быть дифференцированы в зависимости от видов деятельности в соответствии с ОКВЭД2.

Опыт Эстонии, исключившей налог на прибыль из налоговой системы страны, показал, что после его отмены количество убыточных предприятий в стране значительно сократилось [35] ввиду снижения заинтересованности бизнеса в манипулировании расчетами прибыли. Вопросы корректности исчисления прибыли в этом случае переходят прежде всего в сферу интересов собственников организаций.

Уменьшение ставок по страховым взносам во внебюджетные фонды потребует поиска дополнительных источников пополнения бюджетов внебюджетных фондов. При этом важно, чтобы инструменты пополнения данных бюджетов не препятствовали решению задач восстановления экономического роста в стране. 
Увеличение с 2019 г. ставки НДС с 18 до 20\%, повышение акцизов на дизельное топливо и бензин, «фискальные маневры» со снижением таможенных пошлин при одновременном повышении ставок налога на добычу полезных ископаемых, по оценкам ЦБ РФ и Счетной палаты РФ, в совокупности приведут в 2019 г. к росту цен и уровню инфляции до 5-5,5\% [24], что вряд ли желаемый рост ВВП. Принятые правительством РФ новации в налоговой сфере окажутся наиболее чувствительными для домашних хозяйств с низкими доходами.

Налоговые новации в РФ в основном обходят стороной финансово состоятельные домашние хозяйства россиян. Это относится не только к налогу на доходы физических лиц, но и, в частности, к налогу на наследство и дарение ${ }^{1}$, который был отменен в 2006 г. в части имущества, переходящего в порядке наследования, и с отдельными ограничениями в отношении дарения. Указанный налог применяется в большинстве развитых стран мира. Налоговые ставки существенно различаются между странами в зависимости от родства с наследодателем. Например, во Франции ставки налога находятся в диапазоне от 5 до $60 \%$, в Германии - от 7 до $50 \%$, в Италии - от 4 до 8\% [36]. Возвращение налога на наследство и дарение в налоговую систему РФ позволит не только пополнить доходы государственных и муниципальных бюджетов, но и будет способствовать соблюдению принципа справедливости в налогообложении доходов физических лиц [37].

В привилегированном положении находятся в Российской Федерации и лица, осуществляющие отдельные операции с ценными бумагами. В Налоговом кодексе РФ предусмотрено освобождение от налогообложения доходов, полученных организациями, физическими лицами от продажи отдельных категорий акций, долей участия в уставных капиталах организаций. В целях стимулирования долгосрочных инвестиций Федеральным законом от 28.12.2010 г. № 395-ФЗ установлены условия для получения освобождения. Акции (доли) должны:

- быть акциями (долями) российских организаций;

- непрерывно в течение более пяти лет находиться в собственности налогоплательщика.

Федеральным законом от 29.12.2015 г. № 396-Ф3 с 1 января 2016 г. упрощены условия для освобождения от налогообложения доходов, полученных от продажи (погашения) обращающихся акций, а также облигаций, инвестиционных паев российских организаций, относящихся к инновационному сектору экономики. Вопрос результативности освобождения от налогообложения подобных доходов с точки зрения достижения поставленных целей является неоднозначным. По нашему мнению, вопросы налогообложения операций с финансовыми инструментами необходимо с теоретического обсуждения переводить в практическую плоскость.

${ }^{1}$ В Российской Федерации до 2006 г. он назывался налогом с имущества, переходящего в собственность физических лиц в порядке наследования или дарения. 


\section{Выводы}

Российская политика налогового стимулирования инвестиционной активности предприятий и организаций связана, прежде всего, с применением налоговых льгот, иных преференций по налогам, сборам, таможенным платежам; прямой финансовой поддержкой развития отдельных отраслей и сфер деятельности, например поддержкой сельского хозяйства, содействием ипотечному кредитованию. Возникающие же при этом бюджетные дефициты Министерство финансов РФ старается ликвидировать путем наращивания доходной части бюджетов, увеличивая налоговое бремя на бизнес и физических лиц. Это ведет к росту инфляции, которую Банк России пытается решить путем увеличения ключевой ставки, сдерживания роста денежной массы, делая тем самым кредит малодоступным для подавляющей части российского бизнеса. Такая политика не соответствует восстановлению экономического роста в стране, росту инвестиционной активности предприятий.

Новизна результатов проведенного исследования состоит в развитии методологии налогообложения применительно к современной модели функционирования национальной экономики в направлении смещения акцентов на налогообложение ресурсов в целях стимулирования инвестиционной активности предприятий.

Поиск конкретных механизмов налогообложения операций с финансовыми инструментами на финансовом рынке РФ является важнейшей предпосылкой дальнейших исследований с целью создания сбалансированной системы налогообложения реального и финансового секторов национальной экономики.

\section{Лuтература}

1. Налоговые льготы. Теория и практика применения: монография для магистрантов, обучающихся по программам направления «Финансы и кредит» / под ред. И.А. Майбурова, Ю.Б. Иванова. М. : ЮНИТИ-ДАНА, 2014.

2. Майбуров И.А. Проблема идентификации и оценки налоговых расходов: методологический подход к решению // Проблемы экономики (Харьков). 2012. № 4. С. 187-193.

3. Joe Minarik. Tax Expenditures in OECD Counties. OECD, 2009. P. 13. URL: http://www.oecd.org/governance/budgeting/42976288.pdf/ (access date: 08.02.2019).

4. Klemm A. Causes, Benefits and Risks of Business Tax Incentives. IMF WP/09/21. Washington, D.C. : International Monetary Fund, 2009.

5. Holland D., Vann R.J. Income Tax Incentives for Investment // Tax Law and Drafting. 1998. Vol. 2 (Washington: IMF). P. 986-1020.

6. Easson A., Zolt E. Tax Incentives. The World Bank Institute, 2002.

7. Малинина T.A. Оценка налоговых льгот и освобождений: зарубежный опыт и российская практика. М. : Ин-т Гайдара, 2010.212 с.

8. Hall R., Jorgenson D. Tax Policy and Investment Behavior // The American Economic Review. 1967. Vol. 57, № 3. P. 391-414.

9. Tobin J. A General Equilibrium Approach to Monetary Theory // Journal of Money, Credit, and Banking. 1969. Vol. 1 (1). P. 15-29.

10. Eisner R. Tax Policy and Investment Behavior: Further Comment // The American Economic Review. 1970. Vol. 60, № 4. P. 746-752. 
11. Hayashi F. Tobin's Marginal q and Average q: A Neoclassical Interpretation // Econometrica. 1982. Vol. 50 (1). P. 213-224.

12. Djankov S., Ganser T., McLiesh C., Ramalho R. Shleifer A. The Effect of Corporate Taxes on Investment and Entrepreneurship // American Economic Journal: Macroeconomics. 2010. Vol. 2 (3). P. 31-64.

13. Hassett K., Newmark K. Taxation and Business Behavior: a Review of the Recent Literature // Diamond J., Zodrow G. Fundamental Tax Reform: Issues, Choices and Implications. Cambridge : MIT Press, 2008. P. 191-214.

14. Hanlon M., Heitzman Sh. A Review of Tax Research // Journal of Accounting and Economics. 2010. № 50. P. 127-178.

15. Ohrn E. The Effect of Corporate Taxation on Investment and Financial Policy: Evidence from the DPAD // American Economic Journal: Economic Policy. 2018. Vol. 10 (2). P. 272-301.

16. Львова Н.А., Покровская Н.В., Иванов В.В. Социально-ориентированное налогообложение и его восприятие (на материалах опроса будущих экономистов) // Экономические и социальные перемены: факты, тенденции, прогноз. 2017. Т. 10, № 4. С. 196-211.

17. Львова Н.А., Покровская Н.В., Воронова Н.С. Концепция финансовых парадоксов: предпосылки становления и траектории развития // ЭКО. 2017. № 6. С. 164-177.

18. Покровская Н.В. Влияние кризиса на налоговые условия заемного финансирования российских компаний // Экономика и экологический менеджмент. 2015. № 4. C. $70-76$.

19. Jolley J., Lancaster M., Gao J. Tax Incentives and Business Climate: Executive Perceptions From Incented and Nonincented Firms // Economic Development Quarterly. 2015. Vol. 29 (2). P. 180-186.

20. Zwick E., Mahon J. Tax Policy and Heterogeneous Investment Behavior // American Economic Review. 2017. Vol. 107 (1). P. 217-248.

21. Mayoral J., Segura A. Taxes as Determinants of Corporate Investment: Empirical Evidence in Spanish Private Firms // Revista de Contabilidad - Spanish Accounting Review. 2017. Vol. 20, № 2. P. 195-209.

22. Auerbach A., Hines Jr. Investment Tax Incentives and Frequent Tax Reforms // The American Economic Review. 1988. Vol. 78, № 2. P. 211-216.

23. Ivanov V. V., Lvova N.A., Pokrovskaia N.V., Naumenkova S.V. Determinants of Tax Incentives for Investment Activity of Enterprises // Journal of Tax Reform. 2018. Vol. 4, № 2. P. $125-141$.

24. Основные направления бюджетной, налоговой и таможенно-тарифной политики на 2019 год и плановый период 2020 и 2021 годов. URL: https://www.minfin.ru/ru/ statistics/docs/budpol_taxpol/ (дата обращения: 08.02.2019).

25. Офищиальный сайт Федеральной налоговой службы России. URL: www.nalog.ru (дата обращения: 08.02.2019).

26. Федеральная служба государственной статистики // Статистическое обозрение. 2015. № 1 (92).

27. Федеральная служба государственной статистики // Статистическое обозрение. 2018. № 2 (101).

28. Соколов M.M. О причинах стагнации темпов роста экономики в России и необходимости перестройки налогообложения в стране на стимулирование бизнеса к инвестиционной деятельности и методы ее осуществления. URL: https://inecon.org/ docs/2018/Sokolov_Ekonomist_2018_8.pdf (дата обращения: 10.02.2019).

29. Мартынов $A$. Полная доходность российского рынка акций с учетом дивидендов. 12.01.2017. URL: https//www.activeinvestor.pro (дата обращения: 10.02.2019).

30. Соколов M.M. Об уровне налоговой нагрузки в экономике России и о возможностях по ее снижению без сокращения налоговых поступлений // Экономика в промышленности. 2018. Т. 11, № 1. С. 52-62. 
31. Paying Taxes. Data explorer. PWC. URL: https://www.pwc.com/gx/en/services/ tax/publications/paying-taxes-2019.html (дата обращения: 08.02.2019).

32. Много ли в мире стран, где налоговая нагрузка выше, чем в России? URL: https://www.factograph.info/a/28981246.html (access date: 08.02.2019).

33. Информационный портал Главбух. URL: www.glavbukh.ru (дата обращения: 08.02.2019).

34. Кудрин видит риски падения реальных доходов населения. URL: http://tass.ru/ ekonomika/5770366 (дата обращения: 08.02.2019).

35. Кривоблочкий Д. Эстония и ее налоговая система. URL: https//www.impex.academy/nalogovaya -sistema-estonii/ (дата обращения: 08.02.2019).

36. Forbs: Дети олигархов получат \$ 211 млрд от предприятий CCCP. URL: https://sobityadnya.ru/blog/43634359732/privatizatsiya-glazami-Forbs:-Deti-oligarhovpoluchat-\$-211-mlrd?tmd=1 (дата обращения: 08.02.2019).

37. Пансков В.Г. Налог на наследуемое имущество и проблемы справедливости // Финансы. 2018. № 12. С. 32-37.

\section{Tax Incentives Instruments of a Resource-Saving Model of the National Economy}

Vestnik Tomskogo gosudarstvennogo universiteta. Ekonomika - Tomsk State University Journal of Economics. 2019. 46. pp. 174-188.

DOI: $10.17223 / 19988648 / 46 / 12$

Viktor V. Ivanov, Saint Petersburg State University (Saint Petersburg, Russian Federation). E-mail: viktor.ivanov@spbu.ru

Keywords: tax incentives, investment activity, economic growth, tax preferences, financial aid.

The article addresses problem aspects of stimulating Russian companies' investment activity. It is shown that the applied instruments of tax incentives do not provide the desired growth of investments in fixed assets in many spheres of economic activity while the national economy is in stagnation. Alongside with this, we can watch a considerable increase in financial investments on the Russian securities market provided by non-financial companies. The author proves the advisability of switching the accents from taxation of legal entities' income to taxation of resources they use as well as of establishing a balanced system of non-financial and financial companies' taxation.

\section{References}

1. Mayburov, I.A. et al. (2014) Nalogovye l'goty. Teoriya i praktika primeneniya [Tax incentives. Theory and practice of application]. Moscow: YuNITI-DANA.

2. Mayburov, I.A. (2012) The Problem of Tax Expenditures Identification and Evaluation: Methodological Approach. Problemy ekonomiki (Kharkov). 4. pp. 187-193. (In Russian).

3. Minarik, J. (2009) Tax Expenditures in OECD Counties. [Online] Available from: http://www.oecd.org/governance/budgeting/42976288.pdf/. (Accessed: 08.02.2019).

4. Klemm, A. (2009) Causes, Benefits and Risks of Business Tax Incentives. IMF WP/09/21. Washington, D.C.: International Monetary Fund.

5. Holland, D. \& Vann, R.J. (1998) Income Tax Incentives for Investment. Tax Law and Drafting. 2 (Washington: IMF). pp. 986-1020.

6. Easson, A. \& Zolt, E. (2002) Tax Incentives. The World Bank Institute.

7. Malinina, T.A. (2010) Otsenka nalogovykh l'got i osvobozhdeniy: zarubezhnyy opyt $i$ rossiyskaya praktika [Assessment of tax benefits and exemptions: foreign experience and Russian practice]. Moscow: In-t Gaydara.

8. Hall, R. \& Jorgenson, D. (1967) Tax Policy and Investment Behavior. The American Economic Review. 57 (3). pp. 391-414.

9. Tobin, J. (1969) A General Equilibrium Approach to Monetary Theory. Journal of Money, Credit, and Banking. 1 (1). pp. 15-29. 
10. Eisner, R. (1970) Tax Policy and Investment Behavior: Further Comment. The American Economic Review. 60 (4). pp. 746-752.

11. Hayashi, F. (1982) Tobin's Marginal q and Average q: A Neoclassical Interpretation. Econometrica. 50 (1). pp. 213-224.

12. Djankov, S. et al. (2010) The Effect of Corporate Taxes on Investment and Entrepreneurship. American Economic Journal: Macroeconomics. 2 (3). pp. 31-64.

13. Hassett, K. \& Newmark, K. (2008) Taxation and Business Behavior: a Review of the Recent Literature. In: Diamond, J. \& Zodrow, G. (eds) Fundamental Tax Reform: Issues, Choices and Implications. Cambridge: MIT Press.

14. Hanlon, M. \& Heitzman, Sh. (2010) A Review of Tax Research. Journal of Accounting and Economics. 50. pp. 127-178.

15. Ohrn, E. (2018) The Effect of Corporate Taxation on Investment and Financial Policy: Evidence from the DPAD. American Economic Journal: Economic Policy. 10 (2). pp. 272301.

16. L'vova, N.A., Pokrovskaya, N.V. \& Ivanov V.V. (2017) Socially oriented taxation and how it is perceived (case study of a survey of economists-to-be). Ekonomicheskie $i$ sotsial'nye peremeny: fakty, tendentsii, prognoz - Economic and Social Changes: Facts, Trends, Forecast. 10 (4). pp. 196-211. (In Russian). DOI: 10.15838/esc/2017.4.52.11

17. L'vova, N.A., Pokrovskaya, N.V. \& Voronova, N.S. (2017) Kontseptsiya finansovykh paradoksov: predposylki stanovleniya i traektorii razvitiya [The concept of financial paradoxes: prerequisites for the formation and development trajectory]. EKO-ECO. 6 . pp. 164-177. DOI: 10.30680/ECO0131-7652-2017-6-164-177

18. Pokrovskaya, N.V. (2015) Impact of crisis for tax conditions in Russian companies' debt financing. Ekonomika $i$ ekologicheskiy menedzhment - Economics and Environmental Management. 4. pp. 70-76. (In Russian).

19. Jolley, J., Lancaster, M. \& Gao, J. (2015) Tax Incentives and Business Climate: Executive Perceptions From Incented and Nonincented Firms. Economic Development Quarterly. 29 (2). pp. 180-186.

20. Zwick, E. \& Mahon, J. (2017) Tax Policy and Heterogeneous Investment Behavior. American Economic Review. 107 (1). pp. 217-248.

21. Mayoral, J. \& Segura, A. (2017) Taxes as Determinants of Corporate Investment: Empirical Evidence in Spanish Private Firms. Revista de Contabilidad - Spanish Accounting Review. 20 (2). pp. 195-209.

22. Auerbach, A. \& Hines, Jr. (1988) Investment Tax Incentives and Frequent Tax Reforms. The American Economic Review. 78 (2). PP. 211-216.

23. Ivanov, V.V., Lvova, N.A., Pokrovskaia, N.V. \& Naumenkova, S.V. (2018) Determinants of Tax Incentives for Investment Activity of Enterprises. Journal of Tax Reform. 4 (2). pp. 125-141.

24. Ministry of Finance of the Russian Federation. (2018) The main directions of the budget, tax and customs tariff policy for 2019 and the planning period of 2020 and 2021. [Online] Available from: https://www.minfin.ru/ru/ statistics/docs/budpol_taxpol/. (Accessed: 08.02.2019).

25. The official website of the Federal Tax Service of Russia. [Online] Available from: www.nalog.ru. (Accessed: 08.02.2019). (In Russian).

26. Statisticheskoe obozrenie. (2015) 1 (92).

27. Statisticheskoe obozrenie. (2018) 2 (101).

28. Sokolov, M.M. (2018) O prichinakh stagnatsii tempov rosta ekonomiki v Rossii $i$ neobkhodimosti perestroyki nalogooblozheniya $v$ strane na stimulirovanie biznesa $k$ investitsionnoy deyatel'nosti i metody ee osushchestvleniya [On the reasons for the stagnation of the economic growth in Russia, on the need for taxation adjustment in the country to stimulate business to invest and methods of its implementation]. [Online] Available from: https://inecon.org/docs/2018/Sokolov_Ekonomist_2018_8.pdf. (Accessed: 10.02.2019). 
29. Martynov, A. (2017) Polnaya dokhodnost' rossiyskogo rynka aktsiy s uchetom dividendov [Full return on the Russian stock market, taking into account dividends]. [Online] Available from: https//www.activeinvestor.pro. (Accessed: 10.02.2019).

30. Sokolov, M.M. (2018) On the level of the tax burden in the Russian economy and the possibilities to reduce it without reducing tax revenues. Ekonomika $v$ promyshlennosti Economy in the Industry. 11 (1). pp. 52-62.(In Russian). DOI: 10.17073/2072-1633-2018-1052-062

31. PWC. (2019) Paying Taxes. Data explorer. [Online] Available from: https://www.pwc.com/gx/en/services/tax/publications/paying-taxes-2019.html. (Accessed: 08.02.2019).

32. Factograph. (2018) Mnogo li v mire stran, gde nalogovaya nagruzka vyshe, chem v Rossii? [Are there many countries in the world where the tax burden is higher than in Russia?]. [Online] Available from: https://www.factograph.info/a/28981246.html. (Accessed: 08.02.2019).

33. Glavbukh Information Portal. [Online] Available from: www.glavbukh.ru. (Accessed: 08.02.2019). (In Russian).

34. TASS. (2018) Kudrin vidit riski padeniya real'nykh dokhodov naseleniya [Kudrin sees the risks of falling of real incomes of the population]. [Online] Available from: http://tass.ru/ekonomika/5770366. (Accessed: 08.02.2019).

35. Krivoblotskiy, D. (n.d.) Estoniya i ee nalogovaya sistema [Estonia and its tax system]. [Online] Available from: https//www.impex.academy/nalogovaya-sistema-estonii/. (Accessed: 08.02.2019)

36. Sobityadnya.ru. (2018) Forbs: Deti oligarkhov poluchat $\$ 211 \mathrm{mlrd}$ ot predpriyatiy SSSR [Forbes: Children of oligarchs will receive \$ 211 billion from enterprises of the USSR]. [Online] Available from: https://sobityadnya.ru/blog/43634359732/privatizatsiya-glazamiForbs:-Deti-oligarhov-poluchat-\$-211-mlrd?tmd=1. (Accessed: 08.02.2019).

37. Panskov, V.G. (2018) Nalog na nasleduemoe imushchestvo i problemy spravedlivosti [Inherited property tax and equity issues]. Finansy-Finance. 12. pp. 32-37. 